International Journal of Current Advanced Research

ISSN: O: 2319-6475, ISSN: P: 2319 - 6505, Impact Factor: SJIF: 5.995

Available Online at www.journalijcar.org

Volume 6; Issue 3; March 2017; Page No. 2914-2918

DOI: http://dx.doi.org/10.24327/ijcar.2017.2918.0141

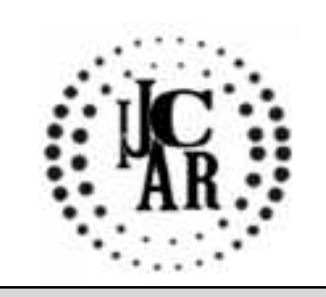

Research Article

\title{
NEED FOR ORTHODONTIC TREATMENT AND SELF-PERCEPTION OF MALOCCLUSION AMONG YOUNG ADULTS IN CHENNAI
}

\section{Nurul Syamimi binti Mohd Azlan Sunil and Saravana Pandian}

Department of Conservative and Endodontics, Saveetha Dental College

\section{A R T I C L E I N F O \\ Article History: \\ Received $16^{\text {th }}$ December, 2016 \\ Received in revised form $24^{\text {th }}$ January, 2017 \\ Accepted $25^{\text {th }}$ February, 2017 \\ Published online $28^{\text {th }}$ March, 2017}

\section{Key words:}

Aesthetic component, Index of Orthodontic Treatment Need, Indian young adults, Orthodontic Need

\begin{abstract}
A B S T R A C T
Aim and Objective: The objective of this study was to investigate the need of orthodontic treatment among young where orthodontic treatment would be sought by a sample of Dental and Law students.
\end{abstract}

Materials and Method: Using the 10-grade esthetic component (AC) scale of the Index of Orthodontic Treatment Need (IOTN), 165 university students (100 dental and 65 law students) selected the level of esthetic impairment that represented the point at which they would seek orthodontic treatment. A questionnaire was answered by both the sample populations. The results obtained were compared between both groups.

Results: The AC photograph Grade 4 and Grade 5 were found to be the most commonly selected threshold photographs by the law students and the dental students, respectively. Subjects who visited the dentist every 6 months, in both groups, were more likely to choose a threshold photograph closer to the attractive end of the scale.

Conclusion: The information regarding the need and demand of orthodontic treatment allows a treatment priority to be set up to allocate appropriate resources. The results indicate that the aesthetic expectations of the dental and non-dental professionals differ so when using the AC of the IOTN the "no need for treatment" category should be Grades 1-3 of the AC, rather than Grades 1-4.

Copyright $₫ 2017$ Nurul Syamimi binti Mohd Azlan Sunil and Saravana Pandian. This is an open access article distributed under the Creative Commons Attribution License, which permits unrestricted use, distribution, and reproduction in any medium, provided the original work is properly nitad

\section{INTRODUCTION}

The dentofacial region contributes crucially to the overall facial appearance and this has long been recognized.[1] Besides that, a well-proportioned facial features, nicely aligned teeth and a pleasing, attractive smile largely contribute to one's self-esteem and self-confidence. There are numerous investigationsthat confirmed the downside-effects of malocclusion, rather than any functional disability, were indeed psychosocial in nature.[4-6]Nonetheless, perceptions of malocclusions are subjective and perceived as more qualitatively than quantitatively, thus, cosmetic impairment of a particular malocclusion is not readily measured.[2] Perception has been defined as the process by which patterns of environmental stimuli are organized and interpreted, while aesthetics is defined as the appreciation or the enjoyment of beauty.[3] Therefore, visual stimuli as tools in communication may be more conceivable thanverbal descriptions when dealing with information related to morphology and the aesthetic significance of variability.[2]

*Corresponding author: Nurul Syamimi binti Mohd Azlan Sunil

Department of Conservative and Endodontics, Saveetha Dental College
It has been demonstrated that standardised dental photographs can be utilized as a legitimate representation of dental attractiveness.[6]

Most occlusal indices define aesthetics, and ultimately orthodontic treatment need from a clinicians perspective only (normative need) without considering the social needs of their patients. There is evidence to support the view that the aesthetic component (AC) of the Index of Orthodontic Treatment Need (IOTN) should also be validated against the opinion of people who are not dental professionals.[7,8] Moreover, grading of attractiveness and cut-off points, the treatment vary as cultural norms for acceptable dental arrangement may differ between countries.[9] Thus, the present study aimed to investigate the orthodontic treatment need of young adults in Chennai and to determine the threshold at which a sample of law students would seek orthodontic intervention and to compare it with the threshold level of intervention suggested by a sample of dental students.

\section{METHOD}

A pretested questionnaire, as shown in Figure 1, consists 10 questions on self-perception of malocclusion, importance of having well-aligned and orthodontic treatment need teeth were distributed to a number of dental from Saveetha Dental 
College and law students of Saveetha School of Law to be filled up. A total of 187 students, both male and female were assessed through this questionnaire.

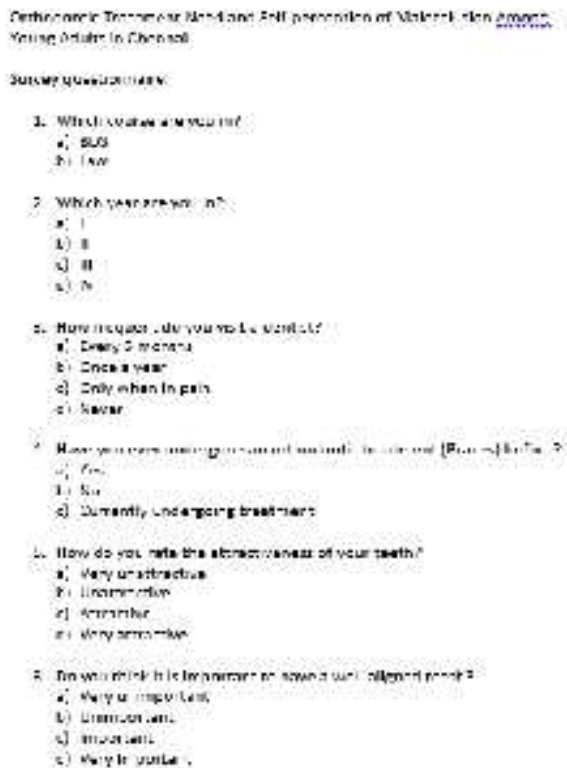

Figure 1 Questionnaire on Orthodontic Need

The questionnaires were distributed and conducted online using Survey Planet (surveyplanet.com) and completed by the participants within 2 days after distribution. Provided in the questionnaire is the $\mathrm{AC}$ of the IOTN, in which participants were instructed to record the $\mathrm{AC}$ grade that indicated the point at which they would seek treatment if the photographs represented their own dentition. In addition, the students also rated the attractiveness of their own teeth (very unattractive, unattractive, attractive, or very attractive) and the importance that they attributed to having straight teeth (very unimportant, unimportant, important, or very important). The subjects were also asked how frequently they attended the dentist (every 6 months, once a year, and only when in pain).The questionnaire also included questions to which the student were asked if they had ever received orthodontic treatment or is currently receiving treatment.

The AC of the IOTN by Brook and Shaw in 1989 was used in this study. It is a series of ten colour photographs arranged according to its attractiveness. Grade 1 represents the most attractive and Grade 10 represents the least attractive [Figure 2]. During the initial development of IOTN to validate the cut-off points representing the different levels of orthodontic treatment need, according to professional opinion of 74 dentists which was used, Grades 1-4 of the AC represent no need for orthodontic treatment, Grades 5-7 represent borderline need, and Grades 8-10, definite need for treatment.[2]

\section{RESULTS}

All 187 students (100\% response) from Saveetha Dental College and Saveetha School of Law participated in the survey. A number of 22 students were not included in the survey as they are either currently receiving orthodontic treatment or had received orthodontic treatment before.
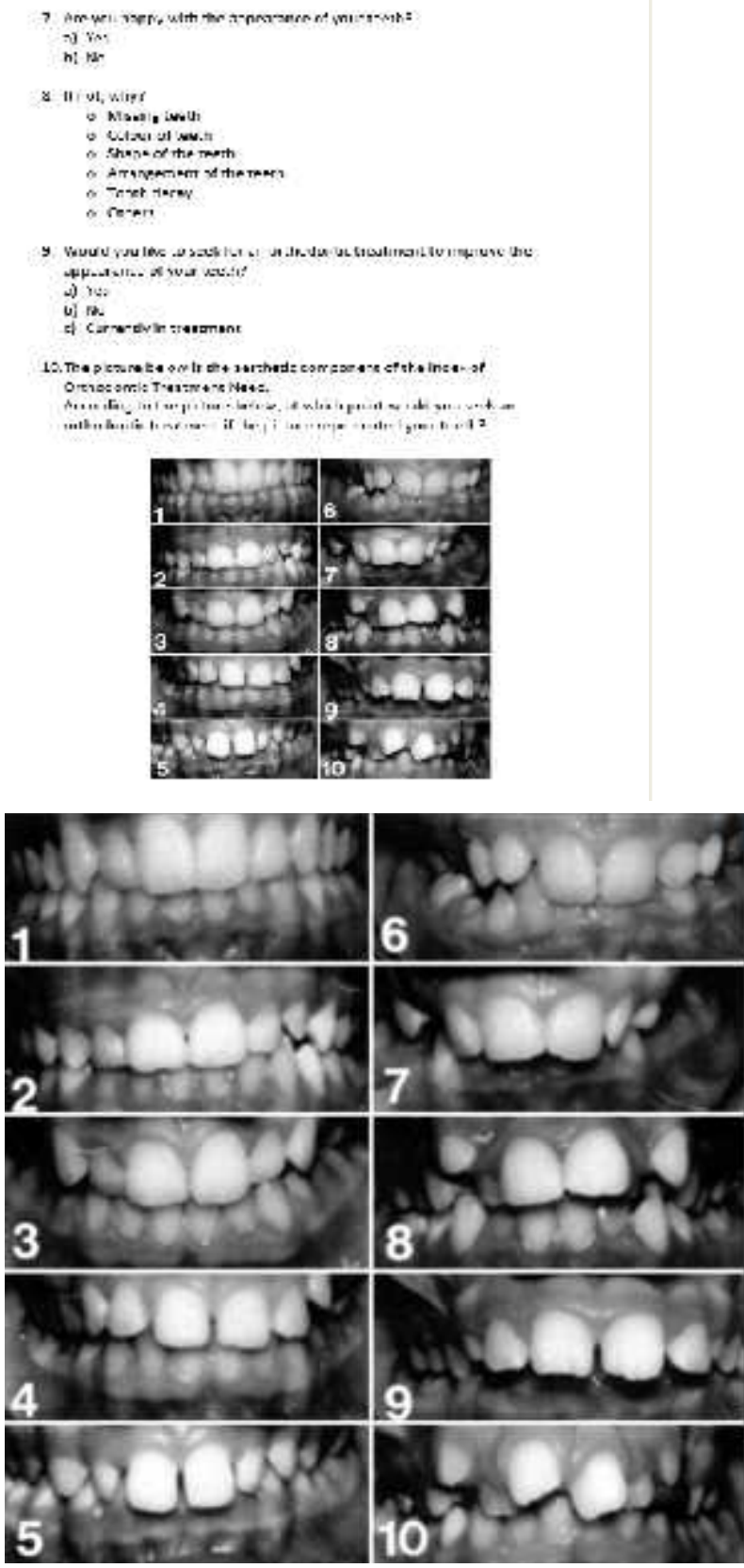

Figure 2 The Aesthetic Component of Index of Orthodontic Treatmen Need

Sixty five law students of Saveetha School of Law, Chennai, who were in their $1^{\text {st }}$ year and $2^{\text {nd }}$ year at the college and one hundred dental students of Saveetha Dental College, Chennai, who were in their $2^{\text {nd }}$ year, $3^{\text {rd }}$ year, and $4^{\text {th }}$ year, completed the questionnaire which determined the point at which they wouldwish to receive orthodontic treatment. The subjects comprised 60 males (law- 22, dental - 38) and 105 females (law - 43, dental - 62) with a median age of 21 years (range of $18-25$ years). 


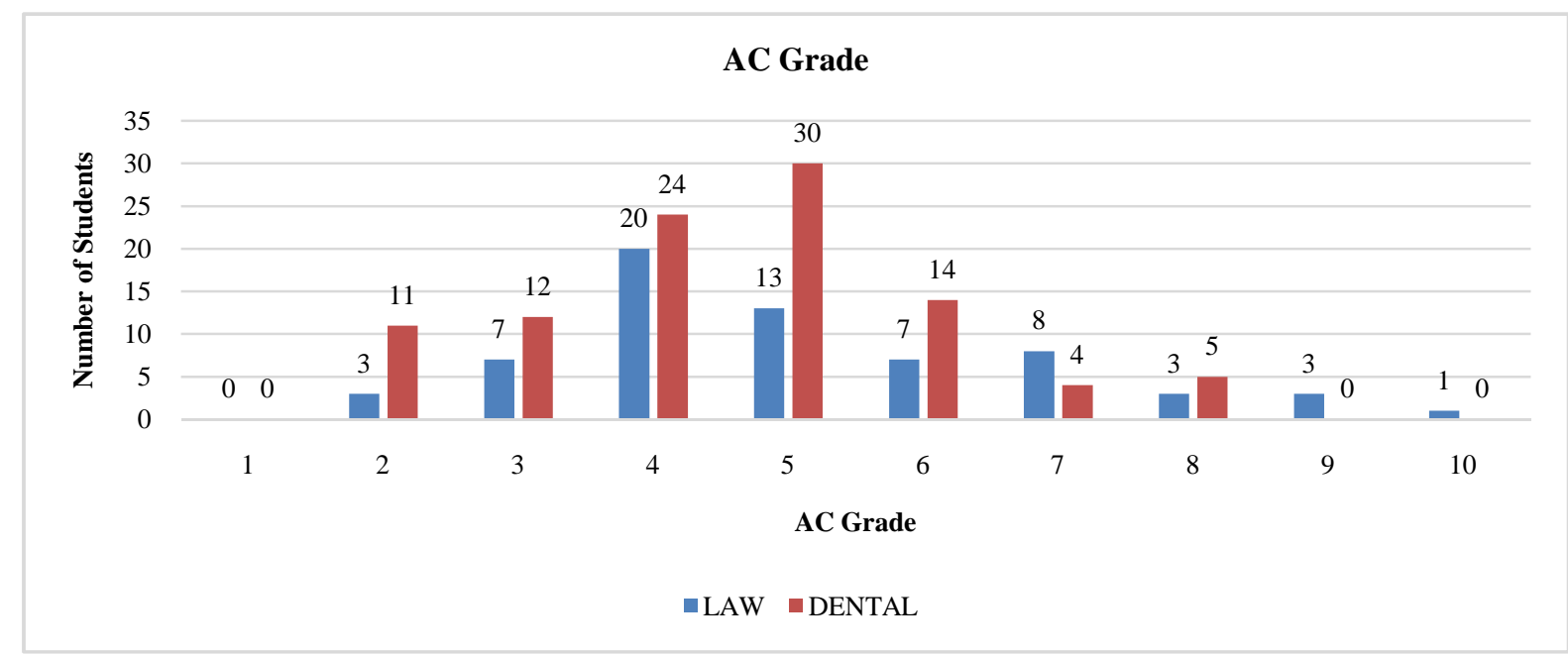

Figure 3 The aesthetic component where orthodontic treatment would be sought

Figure 3 shows the graph of threshold grade selected by the participants. The most commonly selected photograph by law students was the AC Grade 4, in which about twenty (30.7\%) participants selected this grade as the point at which they would seek orthodontic treatment if the photographs represented their dentition. Among the law students, thirty $(46.2 \%)$ reported that they would seek orthodontic treatment by Grade 4 andforty-three $(66.2 \%)$ of the samplereported they would seek orthodontic treatment by Grade 5. Twenty-two $(33.8 \%)$ of the respondents recorded a threshold grade beyond Grade 5.The AC Grade 5 was found to be the most commonly selected threshold photograph by the dental students [Figure 2]. Thirty (30\%) of the sample selected Grade 5 as the point in the scale of severity at which they would seek orthodontic treatment if the photographs had represented their own dentition. Based on the graph constructed, by Grade 5, $100(77 \%)$ dental students reported that they would seek orthodontic treatment and by Grade $6,91 \%$ of the sample would seek orthodontic treatment. Among dental students, only $9(9 \%)$ of the respondents recorded a threshold Grade beyond Grade 6 of the AC. It was observed that those who visited their dentist more regularly chose a cut-off grade closer to the more attractive end of the scale compared with those who attended their dentist less frequently in boththe groups.

The relationship between frequency of dental attendance and the selected threshold grade of the AC is illustrated in Table 1. once a year. The remaining $20(30.8 \%)$ subjects reported that they visit the dentist only when they are experiencing pain. Therefore, the majority of participants (69.3\%) attended the dentist at least once a year.

Among the dental students sixteen subjects (16\%) reported that they attended the dentist every 6 months while a further sixty-two (62\%) subjects reported that they visited their dentist once a year. Twenty-two (22\%) subjects reported that they attended the dentist only when they are experiencing pain. Therefore, the majority of participants (78\%) attended the dentist at least once a year.

The responses to subjects' rating of the attractiveness of own teeth and their opinion on the importance of having straight teeth revealed quite similar results for both the groups [Table $2]$. The majority of the subjects (law $-41.5 \%$, dental - 37\%) considered that their own dentitions were "attractive" [Table 2]. In addition, the majority of respondents (law - 75.4\%, dental - 95\%) also felt it was "important" or "very important" to have straight teeth [Table 3].

\section{DISCUSSION}

[10]A study conducted proved that an orthodontic treatment is mostly seek by patients mainly because of the need to improve their facial features.[11] The Aesthetic Component of Index of Orthodontic Treatment Need the IOTN developed by

Table 1 The relationship between frequency of dental attendance and choice of aesthetic component grade

\begin{tabular}{|c|c|c|c|c|c|c|}
\hline \multirow[t]{2}{*}{ AC Grade } & \multicolumn{3}{|c|}{ No. of Law students (\%) } & \multicolumn{3}{|c|}{ No. of Dental students (\%) } \\
\hline & Every 6 months & Once a year & Only when in pain & Every 6 months & Once a year & Only when in pain \\
\hline 1 & $0(0.0)$ & $0(0.0)$ & $0(0.0)$ & $0(0.0)$ & $0(0.0)$ & $0(0.0)$ \\
\hline 2 & $2(3.1)$ & $1(1.5)$ & $0(0.0)$ & $3(3.0)$ & $5(5.0)$ & $3(3.0)$ \\
\hline 3 & $2(3.1)$ & $2(3.1)$ & $3(4.6)$ & $1(1.0)$ & $7(7.0)$ & $4(4.0)$ \\
\hline 4 & $5(7.7)$ & $10(15.4)$ & $5(7.7)$ & $3(3.0)$ & $15(15.0)$ & $6(6.0)$ \\
\hline 5 & $3(4.6)$ & $7(10.8)$ & $3(4.6)$ & $6(6.0)$ & $19(19.0)$ & $5(5.0)$ \\
\hline 6 & $2(3.1)$ & $3(4.6)$ & $2(3.1)$ & $2(2.0)$ & $10(10.0)$ & $2(2.0)$ \\
\hline 7 & $1(1.5)$ & $4(6.2)$ & $3(4.6)$ & $0(0.0)$ & $3(3.0)$ & $1(1.0)$ \\
\hline 8 & $0(0.0)$ & $1(1.5)$ & $2(3.1)$ & $1(1.0)$ & $3(3.0)$ & $1(1.0)$ \\
\hline 9 & $0(0.0)$ & $2(3.1)$ & $1(1.5)$ & $0(0.0)$ & $0(0.0)$ & $0(0.0)$ \\
\hline 10 & $0(0.0)$ & $0(0.0)$ & $1(1.5)$ & $0(0.0)$ & $0(0.0)$ & $0(0.0)$ \\
\hline Total & 15 & 30 & 20 & 16 & 62 & 22 \\
\hline
\end{tabular}

AC: Aesthetic Component

Among the law students, fifteen subjects (23.1\%) reported that they attended the dentist every 6 months while a further thirty $(46.2 \%)$ subjects reported that they visited their dentist 
Brook and Shaw has been designed to evaluate and measure aesthetic impairment of malocclusion as it provides a standard measure of dental aesthetic impairment and rating of occlusal the professionally defined "no need for treatment" grouping (Grades $1-4$ of the AC).

Table 2 Percentage of Subjects' perception of the attractiveness of their own teeth

\begin{tabular}{ccccc}
\hline & \multicolumn{2}{c}{ Law Students } & \multicolumn{2}{c}{ Dental Students } \\
\hline & $\begin{array}{c}\text { Number of } \\
\text { subjects }\end{array}$ & $\begin{array}{c}\text { Percentage of } \\
\text { sample }(\boldsymbol{\%})\end{array}$ & $\begin{array}{c}\text { Number of } \\
\text { subjects }\end{array}$ & $\begin{array}{c}\text { Percentage of } \\
\text { sample (\%) }\end{array}$ \\
\hline Very unattractive & 7 & 10.8 & 17 & 17.0 \\
Unattractive & 20 & 30.8 & 31 & 31.0 \\
Attractive & 27 & 41.5 & 37 & 37.0 \\
Very Attractive & 11 & 16.9 & 15 & 15.0 \\
Total & 65 & 100 & 100 & 100 \\
\hline
\end{tabular}

Table 3 Percentage of Subjects' perception of the importance of having straight teeth

\begin{tabular}{ccccc}
\hline & \multicolumn{2}{c}{ Law Students } & \multicolumn{2}{c}{ Dental Students } \\
\hline & $\begin{array}{c}\text { Number of } \\
\text { subjects }\end{array}$ & $\begin{array}{c}\text { Percentage of } \\
\text { sample }\end{array}$ & $\begin{array}{c}\text { Number of } \\
\text { subjects }\end{array}$ & $\begin{array}{c}\text { Percentage of } \\
\text { sample }\end{array}$ \\
\hline Very unimportant & 5 & 7.7 & 0 & 0.0 \\
Unimportant & 11 & 16.9 & 5 & 5.0 \\
Important & 37 & 56.9 & 56 & 56.0 \\
Very Important & 12 & 18.5 & 39 & 39.0 \\
Total & 65 & 100 & 100 & 100 \\
\hline
\end{tabular}

discrepency, thus provides the psychosocial need for orthodontic treatment.

In this study, it was found that the females tend to express greater concern about their facial appearance than males in both the sample groups. Previous investigations by Tung and Kiyak, 1998, also detected this gender influence on the threshold chosen for the initiation of orthodontic treatment. A majority of the subjects in both the groups reported that having straight teeth was important or very important. The age group of the sample (mean $=21$ years) was also considered to be sufficiently mature to be able to make a balanced judgment on the relative influence of dental esthetics on social acceptability, self-esteem, and self-confidence. An earlier study found that children were significantly less critical in their esthetic judgments than young adults. [9] Although, orthodontics has traditionally focused on children and adolescents. Adults are increasingly seeking orthodontic treatment, yet very few studies have been carried out in this age group. Many authors consider that orthodontic treatment need studies should be undertaken in the adult population, which is considered sufficiently mature to form a sound judgment of the importance of dental esthetics for social acceptance and of the impact this can have in daily life. Adults are also more emotionally stable, and their concept of dentofacial esthetics is more realistic. [12]

The results indicate that the level of esthetic impairment represented by Grades 6 through to ten was considered to require orthodontic treatment by $100 \%$ of the subjects surveyed in both the groups. The young adults, therefore, agree with the professionals' assessment that individuals with this level of esthetic impairment are in need of orthodontic treatment.

A previous Norwegian study was done on 137 children, 126 of their parents, and 98 young adults who were asked to record if any of the ten dentitions in the $\mathrm{AC}$ required orthodontic correction.[9]The authors found that in the three groups studied, the threshold selected for orthodontic intervention was Grade 5 of the AC. They, therefore, concluded that Norwegian lay people were in agreement with
The different findings between this previous study and the present investigation can be attributed to the difference in the cultural norms for acceptable dental arrangement between different countries.

Nearly, $15.4 \%$ of law students and $23 \%$ of the dental students questioned in the current study felt that they would seek orthodontic treatment for the level of aesthetic impairment represented by Grades 2-3 of the AC. This confirms the high expectations of dental aesthetic perfection among Nepalese young adults. The factors found to influence the choice of threshold for the initiation of orthodontic treatment were the frequency with which the subjects visited their dentist and their opinion about the importance of straight teeth. Those who attended their dentist more frequently (every 6 months) as well as those who considered the importance of having straight teeth tended to have a lower threshold for the initiation of orthodontic treatment in both the groups. This most likely reflects the greater emphasis placed on dental health and dental appearance by regular dental attenders.

\section{CONCLUSION}

The results indicate that the aesthetic expectations of the dental and non-dental professionals differ so when using the AC of the IOTN the "no need for treatment" category should be Grades 1-3 of the AC, rather than Grades 1-4. Some practical suggestions for clinical practice seem justified on the basis of the results of this investigation. Aesthetic ranking scales used in orthodontic treatment need indices should be validated using general population's view who have a good awareness of orthodontic treatment. The results can help establish a socio-cultural standard of reference related to AC scale. Such standards may be utilized in patient education and information and may assist potential orthodontic patients in making informed decisions about treatment need.

\section{References}

1. Shaw, W.C., The influence of children's dentofacial appearance on their social attractiveness as judged by peers and lay adults. American journal of orthodontics, 1981. 79(4): p. 399-415. 
2. Khan, L., et al., Orthodontic treatment need and selfperception of malocclusion among nepalese young adults. Universal Research Journal of Dentistry, 2016. 6(2): p. 123.

3. Giddon, D.B. Orthodontic applications of ps chologicaland perceptual studies of facial esthetics. in Seminars in orthodontics. 1995. Elsevier.

4. Shaw WC, O’Brien KD, Richmond S, Brook P. Quality control in orthodontics: Risk/benefit considerations. Br Dent J 1991;170:33-7.

5. Evans R, Shaw W. Preliminary evaluation of an illustrated scale for rating dental attractiveness. Eur $J$ Orthod 1987;9:314-8.

6. Howells DJ, Shaw WC. The validity and reliability of ratings of dental and facial attractiveness for epidemiologic use. Am J Orthod Dentofacial Orthop 1985;88:402-8

7. Shaw WC, Lewis HG, Robertson NR. Perception of malocclusion. Br Dent J 1975;138:211-6.

8. Prahl-Andersen B. The need for orthodontic treatment. Angle Orthod 1978;48:1-9
9. Stenvik A, Espeland L, Linge BO, Linge L. Lay attitudes to dental appearance and need for orthodontic treatment. Eur J Orthod 1997;19:271-7.

10. Shue-Te Yeh M, Koochek AR, Vlaskalic V, Boyd R, Richmond $\mathrm{S}$. The relationship of 2 professional occlusal indexes with patients' perceptions of aesthetics, function, speech, and orthodontic treatment need. Am J Orthod Dentofacial Orthop 2000;118:421-8

11. Shaw WC. Factors influencing the desire for orthodontic treatment. Eur J Orthod 1981;3:151-62.

12. Hassan AH, Amin Hel-S. Association of orthodontic treatment needs and oral health-related quality of life in young adults. Am J Orthod Dentofacial Orthop 2010;137:42-7.

13. Tung AW, Kiyak HA. Psychological influences on the timing of orthodontic treatment. Am J Orthod Dentofacial Orthop 1998;113:29-39.

\section{How to cite this article:}

Nurul Syamimi binti Mohd Azlan Sunil and Saravana Pandian (2017) 'Need For Orthodontic Treatment And Self-Perception Of Malocclusion Among Young Adults In Chennai', International Journal of Current Advanced Research, 06(03), pp. 2914-2918.DOI: http://dx.doi.org/10.24327/ijcar.2017.2918.0141 